\section{Imprisonment and torture of doctors in Bahrain}

To the Editor: During the months of February and March 2011, as part of the 'Arab Spring', protest action and demonstrations took place in Manama, capital of the Kingdom of Bahrain. When the authorities sought to put down the action, many protesters were injured and some died of their injuries. Those who were injured were admitted to Salmaniya Medical Complex, the main government hospital in Bahrain.

That 48 health care workers at the hospital, in keeping with the Hippocratic Oath, cared for the protesters as they would for any patient was sufficient cause for the arrest, imprisonment and torture of these workers. ${ }^{1}$ The group includes Dr Mahmood Asghar, a paediatric surgical colleague known to members of our Association.

After the health care workers had been imprisoned for 6 months without trial, a military court sentenced them to 15 years' imprisonment. Following an international outcry, this decision was set aside. Unfortunately these workers still face trial in a civilian court, and while awaiting trial are not able to return to work, or to leave the country.

The South African Association of Paediatric Surgeons wishes to express its abhorrence of the sanctioning by the government of Bahrain of these actions against our colleagues, and urges the South African Medical Association and medical colleagues around the world to add their voice in condemnation of these actions of the government of Bahrain.

\section{Colin Lazarus}

President, SA Association of Paediatric Surgeons

colinlaz.paedsurg@gmail.com

1. http://physiciansforhumanrights.org/issues/persecution-of-health-workers/bahrain/

\section{SAMA speaks out about the victimisation of doctors in Bahrain}

To the Editor: Saunders and London ${ }^{1}$ correctly highlight the unjust punishment of doctors in Bahrain who treated people wounded during and after political demonstrations in that country. They have been unjustly subjected to military courts and been meted out sentences that are viciously disproportionate to their supposed infractions. The entire issue is clearly one where a state is abusing its authority and violently crushing any hint of rebellion. Similar incidents have now been reported in Syria, where doctors are being punished for treating so-called opposition rebels. Compounding this trend are reports, emanating from several sources, of doctors being tortured while in detention and women doctors even being threatened with rape while in detention. The issue of state-sponsored torture of doctors is reminiscent of our all-too-painful past in South Africa. The question correctly posed by the authors is why there has been so little outcry from South Africa, with its history of doctors subjected to political abuse. Unfortunately, this is where our agreement with the authors ends. Several statements have been made regarding the alleged inaction by the South African Medical Association (SAMA) on this issue. We need to set the record straight about SAMA's response to date, as follows:

1. A SAMA press statement was released in October 2011 that wholly condemned the actions by the Bahraini Government.

2. A Medigram in this respect was released in October 2011 to members, highlighting the issue.

3. SAMA is a co-signatory on the World Medical Association statement condemning the behaviour of the Bahraini Government in October 2011.
4. SAMA is a co-signatory to the demand by the group called Physician's for Human Rights to the Bahraini King to stop trials and punishment of doctors in Bahrain.

5. In January 2012, the Executive Committee of SAMA discussed the issue and agreed to approach the South African Government via the Department of International Affairs and Co-operation to intervene in this matter, if possible. This approach is ongoing.

SAMA would welcome advice on what further action we could take in this regard, but feels that the assertion that we have done very little is unfair and without foundation. Furthermore, we call on doctors to be aware of such alleged abuses being perpetrated against our colleagues and to condemn them.

\section{Mark Sonderup}

Acting Chair, SAMA

Cape Town

msonderup@samedical.co.za

1. Saunders S, London L. Health professionals should be speaking out about the victimisation of doctors in Bahrain. S Afr Med J 2012;102(3):112.

\section{Legal imperatives for consent for children participating in research}

To the Editor: Concerning 'consent for children participating in research', I wish to make readers aware that my previous statement ${ }^{1}$ that s71 of the National Health Act of $2003^{2}$ was not in force, is no longer the case. A statement from the National Health Research Ethics Council (NHREC) Chairperson Professor D du Toit informs all stakeholders that $\mathrm{s} 71$ of the National Health Act was proclaimed with effect from 1 March 2012. ${ }^{3}$ Professor du Toit makes the point that s71 introduces new requirements for health research, 'including (1) written consent (2) consent from a parent or guardian for research with children (3) "therapeutic research" should be in a child's best interest and (4) consent from the Minister must be obtained for "non-therapeutic research" with children'. He further elaborates that 'regulations are yet to be issued providing greater detail and operational guidance to RECs, particularly for the latter requirement'. I deduce that the Minister will probably soon delegate the consent for non-therapeutic research on children to an appropriately defined body such as the NHREC. The ethical imperatives ${ }^{4}$ that I raised in my previous letter are now legal imperatives in our country.

\section{Shan Naidoo}

Department: Community Health

Member of the HREC (Medical)

Faculty of Health Sciences

University of the Witwatersrand

Johannesburg

shan.naidoo@wits.ac.za

1. Naidoo S. Consent for children participating in research. S Afr Med J 2012;102(3):110.

2. National Department of Health. The National Health Act 61 of 2003. Pretoria: Government Printer, 2003.

3. Statement from the Council on Proclamation of s71 of National Health Act. Pretoria: National Health Research Ethics Council, Department of Health, 2012.

4. National Department of Health. Ethics in Health Research: Principles, Structures and Processes. Pretoria: Government Printer, 2006.

\section{Stem cell therapy and amyotrophic lateral sclerosis}

To the Editor: We have been made aware of several patients with neurological diseases attending stem cell therapy centres, and in particular individuals with amyotrophic lateral sclerosis (ALS). The opening of stem cell clinics in South Africa has led to an increased 
number of patients pursuing this therapy at great financial cost and with high expectations. Regarding this technology, we would like to emphasise the following:

1. There is a complete absence of sound clinical evidence for the efficacy of stem cell therapy for ALS and neurodegenerative diseases in general. No randomised controlled studies or even open-label studies with long-term follow-up exist. Furthermore, a prospective case series in the Netherlands showed no benefit from treatment with olfactory ensheathing cells in patients with ALS. ${ }^{1}$

2. Long-term safety data on the use of stem cell therapy in neurological disorders are lacking.

3. Currently, the main utility for stem cell technology in neurological disorders is the ability to offer human in vitro models for understanding disease mechanisms and facilitating drug discovery. Although the potential for cell-based therapy exists, current claims of efficacy in ALS and other neurodegenerative disorders are premature and unsubstantiated.

We have strong scientific, ethical and economic objections to clinics offering stem cell therapy on a commercial basis, as well as medical practitioners recommending (or not advising against) this modality for neurological disorders. Patients with incurable diseases such as ALS are desperate and emotionally vulnerable to the claims of institutions allegedly being able to heal a number of diseases that modern medicine is unable to. Although we respect their autonomy and right to self-determination, patients are seldom equipped to assess the evidence for or against different treatment modalities, and are therefore reliant on medical professionals in decisionmaking. Moreover, regulations guiding stem cell research and therapy are sorely lacking in South Africa. ${ }^{2}$ It is therefore the healthcare professional's moral duty to present patients and their families with relevant information in an understandable manner. In the case of stem cell therapy, this involves a thorough discussion about the absence of scientific evidence and the likelihood that substantial sums will be paid by patients for no discernible benefit. Failing to do so, in our view, is unethical and not in the best interests of the patient.

\section{Franclo Henning \\ Jonathan Carr \\ Division of Neurology \\ Tygerberg Academic Hospital/Faculty of Health Sciences, Stellenbosch University fhenning@sun.ac.za}

1. Piepers S, van den Berg LH. No benefits from experimental treatment with olfactory ensheathing cells in patients with ALS. Amyotroph Lateral Scler 2010;11(3):328-330 [PMID: 20433414].

2. Pepper M. The stem cell regulatory environment in South Africa: cause for concern. S Afr Med J 2009;99(7):505-507 [PMID: 20460017].

\section{Hydatid cysts of the breast and parotid gland}

To the Editor: We report 2 interesting cases of hydatid cysts in unusual sites: in the breast and the deep lobe of the parotid gland.

Hydatid cysts are an infectious disease caused by the larval stage of the cestode Echinococcus. Humans are mostly affected by $E$. granulosus as incidental intermediate hosts. The liver (70\%) and lungs (25\%) are most commonly affected, with the spleen, heart, kidneys, bone, nervous system and soft tissue less frequently affected. ${ }^{1}$ Even in endemic areas, hydatid disease of the head, neck and breast is extremely rare. The incidence of hydatid cyst in the breast has been reported as $0.27 \% .^{2}$ No parotid gland incidence figures are available.

A 24-year-old woman from Van Wyksvlei was referred to the surgical clinic with a lump in the superolateral quadrant of the left breast. Fine-needle aspiration was performed at a local clinic before referral to the surgical clinic; parasitic hooklets were observed, diagnosing an Echinococcus cyst. Chest X-ray (CXR) and abdominal sonar showed no other cysts. Pre-operative albendazole was administered and the cyst was removed by excision biopsy (Fig. 1) There were no postoperative complications.

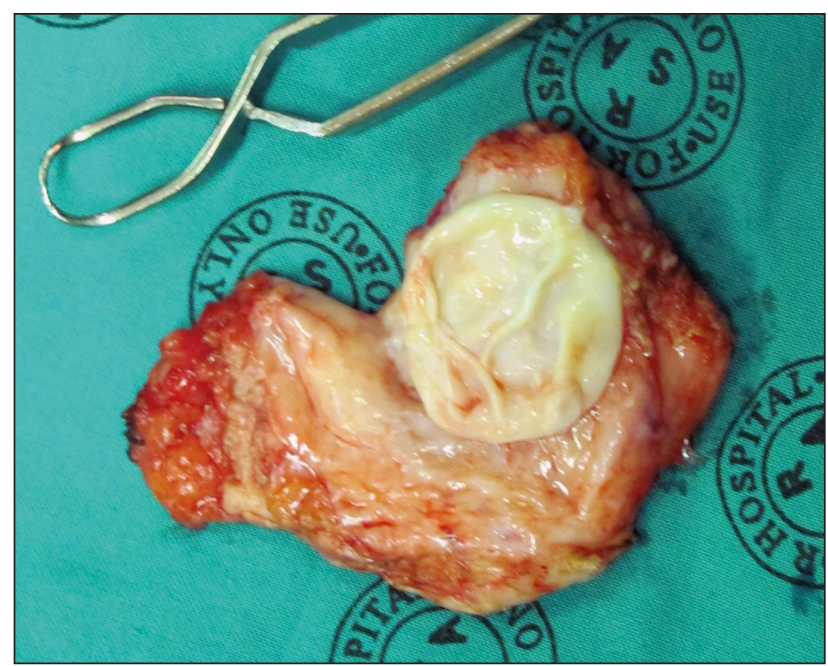

Fig.1. Hydatid cyst excised from the breast.

In the second case, an HIV-negative 20-year-old man from Britstown was referred with a cystic mass in the right parotid area. The cyst, present for about 2 years, had fluctuated in size. It appeared superficial on examination. In the absence of a radiologist at the facility, informed consent was obtained for excision of the cyst with or without superficial parotidectomy. On excision, the cyst appeared to extend into the deep lobe of the parotid gland. Superficial parotidectomy and excision of the cyst was performed without injury to the facial nerve. Histology confirmed normal superficial parotid tissue and an Echinococcus cyst. CXR and abdominal sonar showed no other cysts. The patient was given albendazole and discharged; he returned once for follow-up.

Hydatid disease is a prevalent parasitic infection in sheep-rearing areas such as the Northern Cape. Although hydatid cysts in the head, neck and breast are extremely rare, Echinococcus infection should be considered as a differential diagnosis in patients from endemic areas.

Johlene du Plessis

Central Karoo Hospital

De Aar

Northern Cape

johlene_dup@yahoo.com

1. Ahmad S, Jalil S, Saleem Y, Suleman BA, Chughtai N. Hydatid cysts at unusual sites: reports of two cases in the neck and breast. J Pak Med Assoc 2010;60(3):232-234.

. Epstein NA. Hydatid cyst of the breast: diagnosis using cytological techniques. Acta Cytol 1969:13(7):420-421.

\section{Correction}

We regret that an error occurred in the March 2012 issue of SAMJ. The citation in the abstract of the article 'Dyer SJ, Kruger TF. Assisted reproductive technology in South Africa: First results generated from the South African Register of Assisted Reproductive Techniques' should have read 'S Afr Med J 2012;102:167-170.' The online version was corrected on 11 May 2012. 